University of Montana

ScholarWorks at University of Montana

9-2005

\title{
Evolution of Morphological Integration: Developmental Accommodation of Stress-Induced Variation
}

\author{
Alexander V. Badyaev \\ Kerry R. Foresman \\ University of Montana - Missoula, foresman@mso.umt.edu \\ Rebecca L. Young
}

Follow this and additional works at: https://scholarworks.umt.edu/biosci_pubs

Part of the Biology Commons

Let us know how access to this document benefits you.

\section{Recommended Citation}

Badyaev, Alexander V.; Foresman, Kerry R.; and Young, Rebecca L., "Evolution of Morphological Integration: Developmental Accommodation of Stress-Induced Variation" (2005). Biological Sciences Faculty Publications. 205.

https://scholarworks.umt.edu/biosci_pubs/205

This Article is brought to you for free and open access by the Biological Sciences at ScholarWorks at University of Montana. It has been accepted for inclusion in Biological Sciences Faculty Publications by an authorized administrator of ScholarWorks at University of Montana. For more information, please contact scholarworks@mso.umt.edu. 


\title{
Evolution of Morphological Integration: Developmental Accommodation of Stress-Induced Variation
}

\author{
Alexander V. Badyaev, ${ }^{1, *}$ Kerry R. Foresman, ${ }^{2}$ and Rebecca L. Young ${ }^{1}$
}

1. Department of Ecology and Evolutionary Biology, University of Arizona, Tucson, Arizona 85721;

2. Division of Biological Sciences, University of Montana,

Missoula, Montana 59812-1002

Submitted June 22, 2004; Accepted April 8, 2005;

Electronically published July 13, 2005

Online enhancement: appendix.

ABSTRACT: Extreme environmental change during growth often results in an increase in developmental abnormalities in the morphology of an organism. The evolutionary significance of such stressinduced variation depends on the recurrence of a stressor and on the degree to which developmental errors can be accommodated by an organism's ontogeny without significant loss of function. We subjected populations of four species of soricid shrews to an extreme environment during growth and measured changes in the patterns of integration and accommodation of stress-induced developmental errors in a complex of mandibular traits. Adults that grew under an extreme environment had lower integration of morphological variation among mandibular traits and highly elevated fluctuating asymmetry in these traits, compared to individuals that grew under the control conditions. However, traits differed strongly in the magnitude of response to a stressor-traits within attachments of the same muscle (functionally integrated traits) had lower response and changed their integration less than other traits. Cohesiveness in functionally integrated complexes of traits under stress was maintained by close covariation of their developmental variation. Such developmental accommodation of stress-induced variation might enable the individual's functioning and persistence under extreme environmental conditions and thus provides a link between individual adaptation to stress and the evolution of stress resistance.

Keywords: developmental plasticity, functional integration, modularity, Sorex, stress, variation.

Exposure to environments outside the normal range experienced by a population is commonly associated with

\footnotetext{
* Corresponding author; e-mail: abadyaev@email.arizona.edu.
}

Am. Nat. 2005. Vol. 166, pp. 382-395. (C) 2005 by The University of Chicago. 0003-0147/2005/16603-40501\$15.00. All rights reserved. an increase in phenotypic and genetic variation in organismal traits (Bijlsma and Loeschcke 1997; Hoffmann and Parsons 1997; Hoffmann and Hercus 2000; Price et al. 2003). Increased stress-induced variation is either a product of the increase in generation of novel genetic and phenotypic variation (Wills 1983; Jablonka and Lamb 1995; Caropale 1999; Imasheva 1999; Hadany and Beker 2003) or, more often, especially in morphological traits, a result of reduction in the strength of regulatory mechanisms that release previously accumulated but unexpressed variation (Bradshaw and Hardwick 1989; Eshel and Matessi 1998; Gibson and Wagner 2000; Lipson et al. 2002; Schlichting and Smith 2002; Rutherford 2003). It is often suggested that increased stress-induced variation is a prerequisite for novel adaptations under changed environments (e.g., Siegal and Bergman 2002). However, for stress-induced modifications to have evolutionary significance, they have to be inherited and to persist in a sufficient number of individuals within a population (WestEberhard 1989, 2003; Oyama 2000). Thus, stress-induced variation has to be accommodated by an organism without reducing its functionality, so that an organism can survive a stressor and reproduce. Yet it is not clear how such accommodation is accomplished.

Organisms can maintain functionality in stressful environments by channeling stress-induced developmental variation through buffering of some organismal functions while increasing the flexibility of others (Alberch 1980; Lauder 1981; Nijhout 2002). Proximately, greater flexibility of individual systems is produced by lessening their homeostatic integration (West-Eberhard 2003); such a decrease might enhance the range of performance of individual organismal systems and ultimately increase organismal capacity to adapt to changing conditions (reviewed in Rutherford 2003; Badyaev 2005). However, the mechanisms behind differences of organismal systems in their capacity to buffer or accommodate stress-induced variation are poorly understood. On the one hand, buffering of a stressor might be a consequence of developmental complexity rather than an evolved stress resistance mechanism such that developmental or functional complexity can lead directly to 
resilience to stressors (Baatz and Wagner 1997; Rice 1998; Waxman and Peck 1998; Meiklejohn and Hartl 2002; Siegal and Bergman 2002). Under this scenario, the complexes of traits that share the greatest number of developmental interactions (i.e., the most developmentally integrated) should be the most able to maintain functionality and to accommodate the effects of stress during ontogeny.

On the other hand, an organism's ability to function in different environments requires the ability to track and respond to environmental change (Waddington 1941; Schmalhausen 1949; Wagner et al. 1997; Eshel and Matessi 1998; Ancel 1999; Schlichting and Smith 2002). For example, in some species different life stages or populations vary in bite force and corresponding muscle attachments in relation to prey characteristics (reviewed in Herring 1993; Herring et al. 2001; Hallgrímsson et al. 2004), and species differ in the ability to accommodate such environmentinduced changes (Meyer 1990; Smits et al. 1996a, 1996b; Thompson et al. 2003). An evolved system that completely shields an organism from potential stressors during development will restrict its ability to recognize and capacity to incorporate favorable environmental change (Wagner et al. 1997; Ancel 1999). Critical to the understanding of the evolution of stress response is the knowledge of functional and developmental integration among organismal components as well as the extent and occurrence of extreme environments.

Here we experimentally examine the interaction between functional and developmental integration and organismal response to an environmental stressor. We investigate patterns of integration and accommodation in developmental variability and in stress-induced developmental errors (measured as a fluctuating asymmetry) in bilaterally symmetrical lower mandibles of four closely related species of soricid shrews (Sorex monticolus, Sorex vagrans, Sorex cinereus, and Sorex hoyi). Shrews are particularly suited for the study of accommodation of stressinduced variation because most growth and ossification of their foraging apparatus takes place after birth and temporally coincides with the onset of functional use (Foresman 1994). Thus, there is a rare opportunity to examine the interaction between stress-induced variation during development and patterns of integration imposed by functional requirements. We first show that stressful conditions during development lead to a greater magnitude of developmental errors in the components of the foraging apparatus. Second, we show that within functional complexes (here with the muscle attachments), the expressed response to a stressor is lower than among other traits, whereas the coordination of developmental errors among individual characters is higher. We also show that although cohesiveness among traits lessens under stressful conditions, it remains high in the functional complexes because of the compensation for and accommodation of developmental errors among individual components of these complexes. We discuss the importance of developmental accommodation of stress-induced variation for the maintenance of organism functionality in extreme environments.

\section{Material and Methods}

\section{Data Collection}

The study was carried out on eight experimental plots (6$28 \mathrm{ha}$ ) located in the Swan River Valley of western Montana. Each study site contained control plots (untreated at the time of sampling) and plots where forest overstory (250-500 trees per hectare) was removed and debris was burned by Plum Creek Timber Company the summer before sampling. Study sites were surrounded by large, contiguous forested stands. Previous work showed that the vegetation removal treatment strongly modifies site microclimate, alters food resources and foraging efficiency of shrews, and results in both an increase in developmental instability of shrew embryos and a decrease in individual condition of adult shrews (Badyaev et al. 2000). All four coexisting shrew species (Sorex monticolus, Sorex vagrans, Sorex cinereus, and Sorex hoyi) were trapped with pitfall traps or Sherman live traps. Sherman live traps were arrayed in $10 \times 10$ grids, spaced at $10-\mathrm{m}$ intervals with one trap per station, and baited with rolled oats. Trapping grids were run for four consecutive 24 -h periods and checked twice each day. In addition, three pitfall arrays containing four unbaited pitfalls each were placed across the core of each plot surrounding live trap grids and were checked once per day. We aged captured shrews on the basis of tooth wear (Dannelid 1994) and restricted our analyses to 2-3-month-old shrews that were born in May-June of the year of sampling.

We obtained data on 726 individuals of four species: $S$. monticolus (control: 52 males and 50 females; vegetation removal [VR]: 45 males and 41 females), S. vagrans (control: 53 males and 64 females; VR: 48 males and 59 females), S. cinereus (control: 46 males and 43 females; VR: 74 males and 44 females), and S. hoyi (control: 28 males and 34 females; VR: 17 males and 28 females). The skulls were cleaned in a dermestid beetle colony, and the left and right sides of the lower mandibles were separated. We photographed images of each side of each mandible under $7.5 \times$ magnification, using an Olympic SZH stereo photomicroscope. The analyses of digital images were conducted with Mocha 1.2 and SigmaScan 5.0 Pro software (Jandel Scientific). 

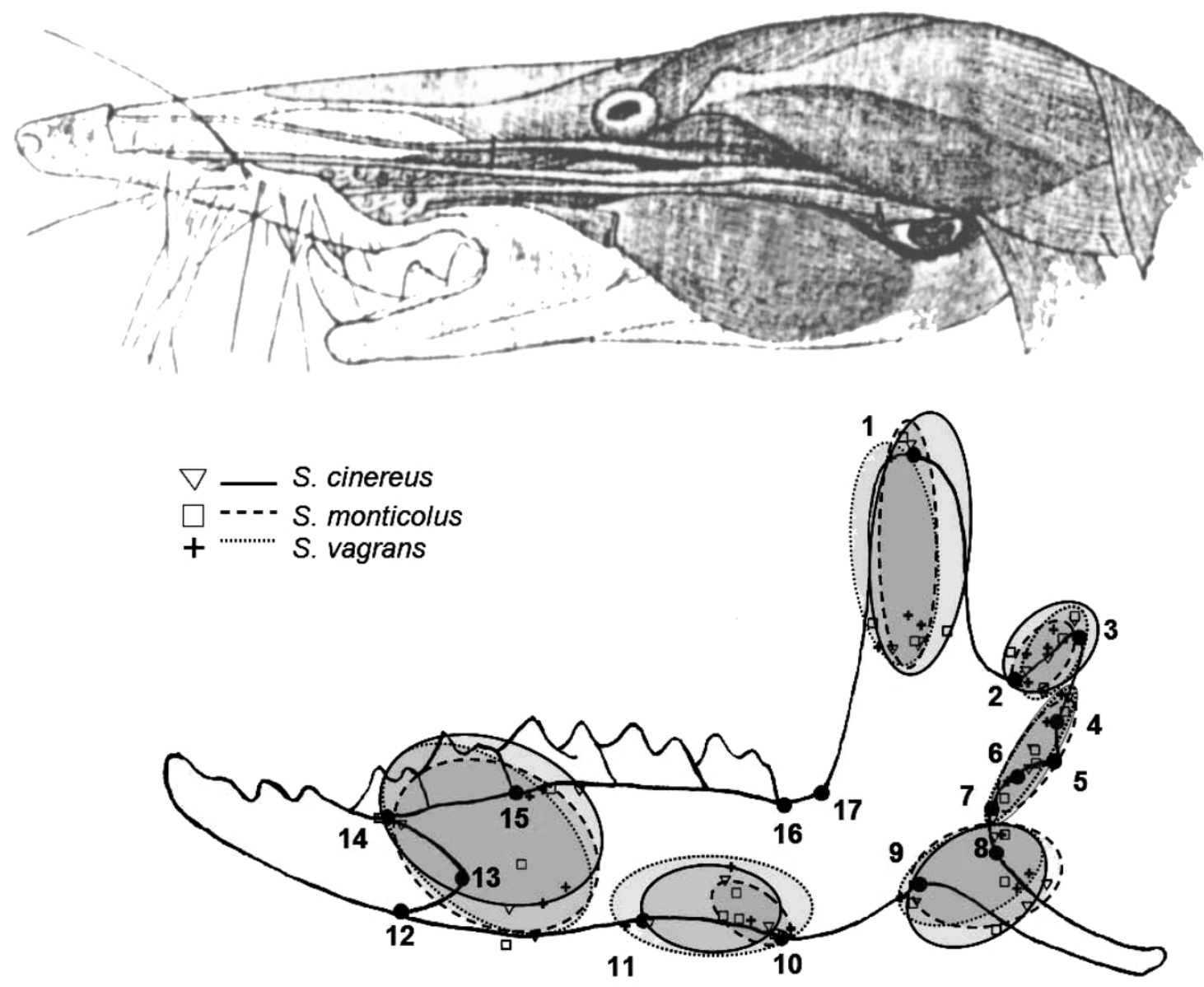

Figure 1: Sorex shrew skull and outline of the lower mandible showing 17 homologous landmarks and the six muscle attachment regions for species used in this study. Muscle attachment regions are shown as the within-species (average among individuals of both sexes) highest, lowest, leftmost, and rightmost locations of muscle attachments and ellipsoids of muscle attachment coordinates for each species. Coordinates of the muscle attachment locations, landmarks, and jaw outline are transformed by a single Procrustes superimposition to account for the effect of size on shape among these species. Overlap in ellipsoids indicates shape overlap of muscle attachment regions among species. Mandibular linear measurements $(\mathrm{n}=$ nonintegrated, not involved in the attachment of the same muscle; $\mathrm{f}=$ functionally integrated, involved in the attachment of the same muscle, see "Material and Methods" for details) were as follows: n1: 1-2, n2: 1-9, n3: 3-4, n4: 8-17, n5: 10-13, n6: 10-16, n7: 11-15, n8: 11-16, n9: 12-13, f1: $2-3$, f2: 4-5, f3: 4-6, f4: 5-8, f5: 8-9, f6: 13-14, f7: 14-15, f8: 10-11, and f9: 13-15.

\section{Delineation of Muscle Attachments and Landmark Data Analysis}

The data were coordinates of homologous morphological landmarks, from which 18 linear measurements were selected (see Badyaev and Foresman 2000 and Badyaev et al. 2000 for details of landmark selection). Within- and among-species variation in muscle attachments were determined by dissection of freshly collected shrews of three species (S. cinereus, S. monticolus, and S. vagrans) and by comparison with those previously described in exploratory analysis of all four species under this study and with closely related species (Ärnbäck-Christie-Linde 1907; Gaughran 1954; Fearnhead et al. 1955; Sharma 1958; Dötsch 1985,
1986; Badyaev and Foresman 2000). We described the following associations between muscle attachment areas and landmarks used in this study (fig. 1): Musculus temporalis attachment on the coronoid process in all species and all individuals includes landmark 1. Musculus temporalis attachment on the condyloid process in all species and all individuals includes landmarks 2 and 3. Musculus masseter attachment on condyloid process in S. cinereus involves landmarks $4-6$ and in some individuals also includes landmark 7; in S. monticolus it involves landmarks 4-7; in $S$. vagrans, landmarks 5-7 and, in some individuals, also landmark 4. Musculus masseter and Musculus pterygoideus internus attachment on the angular process involves land- 
marks 8 and 9 in S. cinereus and S. vagrans; in S. monticolus it always involves landmark 9 and, in some individuals, also landmark 8. Musculus digastricus attachment on the mandibular body always involves landmark 10 in S. monticolus; in S. cinereus it involves landmark 10 in some individuals and landmark 11 in other individuals; in S. vagrans it always involves landmark 11 and, in some individuals, also landmark 10. Musculus buccinator attachment on the mandibular body (mental foramena to incisor) in all species and all individuals involves landmarks 12-15 (fig. 1).

Each cleaned mandible was repositioned and digitized three times to distinguish variance resulting from the positioning of a mandible under the microscope from variance from repeated measures of already scanned images. We used repositioning error for mean squares error $\left(\mathrm{MS}_{\text {error }}\right)$ in our analysis (Badyaev and Foresman 2000), except for the effect of treatment on fluctuating asymmetry, where $\mathrm{MS}_{\text {individual }}$ was used (see below). Repeated measures were separated by several measurement sessions, and mandible photography (by a research technician) and mandible measurements (by A.V.B.) were conducted without knowledge of treatment, sex, or species of a measured animal. To account for size differences among species, the landmarks of muscle attachments (fig. 1) were transformed by Procrustes superimposition (see below), and residual shape coordinates were used in further analyses. Landmarks associated with the attachment of the same muscle were considered functionally integrated. Landmarks either outside of muscle attachment areas or associated with the attachment of different muscles were identified as nonintegrated. Figure 1 shows consensus areas of muscle attachments in three study species. We did not have sufficient data to de novo describe the muscles' attachments in $S$. hoyi; however, because of the similarity in muscle attachment areas among these closely related species (fig. 1), we assigned the landmarks of $S$. hoyi to the functional integration categories based on those confirmed for the other three Sorex species in this study and on limited data on muscle attachment in specimens of S. hoyi (fig. 1).

To calculate the mandible's centroid size, we applied a single Procrustes superimposition (generalized orthogonal least squares fit; Rohlf and Slice 1990) to align simultaneously the landmark configurations from all species, treatments, individuals, body sides, and replicas (after Klingenberg and McIntyre 1998). Before this superimposition, left mandibles were reflected to their mirror images by assigning a negative sign to their $x$-coordinates. Residual shape coordinates were used in all analyses.

Fluctuating asymmetry (FA) was calculated from between-landmark measurements (fig. 1). Each landmark distance selected for this study showed significant and repeatable FA and was tested for outliers, directional asym- metry, deviation from normal distribution (Palmer and Strobeck 2003), and shared point dependence (see Badyaev and Foresman 2000). Natural log-transformed values of the left and right sides were used to control for size dependence. We used Levene's test (PROC GLM option, SAS 9.0) to test for significant differences in heterogeneity of FA among traits and between treatments within individuals (fig. 3) and a two-tailed $t$-test or $F$ ratio tests (PROC GLM or PROC ANOVA in SAS 9.0) to test for difference in the means of traits between the treatments (fig. 2), percentage increases in FA of integrated and nonintegrated groups of traits (fig. 4), and significance of individual terms (table 1 ). Mean squares used in the denominator of the $F$ ratio in Levene's tests of FA differences between treatments and group of traits are given in Palmer and Strobeck (2003, p. 310; see also SAS Institute 1989). The coefficient of integration for size and fluctuating asymmetry traits was computed as $I=\left[\sum\left(\lambda_{i}-1\right)^{2} /\left(n^{2}-n\right)\right]^{1 / 2}$ (Cheverud et al. 1983), where $n$ is the number of traits and $\lambda_{i}$ is an eigenvalue of the correlation matrix of the normalized data. Statistical significance of the integration coefficient was obtained by resampling, with replacement, of the withinprincipal component loadings (1,000 samples; Badyaev and Foresman 2000). For ANCOVA (table 1), sex-related variation was removed from the data in general linear models, and standardized residuals were used.

Table 1: Sources of variation in mandible centroid size in four species of Sorex shrews

\begin{tabular}{lrrrr}
\hline Species, source & Variance $(\%)$ & \multicolumn{1}{c}{ MS } & $F$ & $P$ \\
\hline Sorex monticolus: & & & & \\
Treatment & 29.13 & $84,083.49$ & 7.65 & $\mathbf{. 0 1 1}$ \\
Individual & 39.10 & $10,990.04$ & 4.25 & $\mathbf{. 0 0 0}$ \\
Side & 3.89 & $7,716.27$ & 2.97 & .103 \\
Side $\times$ individual & 27.84 & $2,598.07$ & 1.22 & $\mathbf{. 0 0 1}$ \\
Sorex vagrans: & & & & \\
Treatment & 6.09 & $30,270.02$ & 4.13 & .050 \\
Individual & 49.98 & $7,326.49$ & 4.53 & $\mathbf{. 0 0 0}$ \\
Side & 5.10 & $2,750.30$ & 1.72 & .198 \\
Side $\times$ individual & 38.77 & $1,617.67$ & 2.56 & $\mathbf{. 0 0 0}$ \\
Sorex cinereus: & & & & \\
Treatment & .07 & 31.42 & .02 & .892 \\
Individual & 59.05 & $1,700.97$ & 6.25 & $\mathbf{. 0 0 0}$ \\
Side & 1.85 & 583.10 & 2.14 & .148 \\
Side $\times$ individual & 36.52 & 272.00 & 1.94 & $\mathbf{. 0 0 1}$ \\
Sorex hoyi: & & & & \\
Treatment & 10.12 & $28,271.12$ & 5.18 & $\mathbf{. 0 1 0}$ \\
Individual & 48.98 & $6,906.41$ & 6.03 & $\mathbf{. 0 0 0}$ \\
Side & 2.10 & $2,158.70$ & .98 & .198 \\
Side $\times$ individual & 38.79 & $1,410.67$ & 3.16 & $\mathbf{. 0 0 0}$ \\
\hline
\end{tabular}

Note: Shown are percentage of total variance due to treatment, individual, side, and side $\times$ individual interaction and observed mean squares (MS). $F$ values are from ANOVA, where effects of sex were removed before analyses. Bold $P$ values indicate statistical significance. 


\section{Results \\ Effects of Stress on Size and Fluctuating Asymmetry in Mandible Traits}

Mandible size (centroid) of shrews raised under the stressful conditions was smaller in female Sorex monticolus (control: $860.06 \pm 40.55$ [SD] $\mathrm{mm}^{2}$; stress: $785.73 \pm 41.33, t=$ 5.19, $P<.001$ ), male Sorex vagrans (control: $854.58 \pm$ 53.40; stress: $819.13 \pm 32.19, t=2.27, P=.04)$, and male Sorex hoyi (control: $560.01 \pm 20.55$; stress: $440.70 \pm$ $31.33, t=6.07, P<.001$; fig. 2; table 1). With the exception of female $S$. monticolus (fig. $2 A$ ), the size of most individual mandible traits did not differ between shrews raised under the two treatments. In all four species, there were strong changes in FA in jaw centroid and in individual traits (table 1; fig. 3; tables A1, A2 in the online edition of the American Naturalist); however, traits differed strongly in their reaction to stress, from no change to a more than $200 \%$ increase in some traits (e.g., $\mathrm{f} 4$ vs. $\mathrm{n} 4$ in male $S$. hoyi; fig. 3). For example, in S. monticolus, stress-induced change in FA varied from a $50 \%$ increase in $\mathrm{f} 3$ to a $17.7 \%$ decrease in $\mathrm{n} 1$ (table 1; fig. 3A). Similarly, in S. hoyi, the average change in FA in response to stress varied from a $62 \%$ increase in $\mathrm{f} 1$ to just a $2 \%$ increase in $\mathrm{n} 5$ (tables A1, A2; fig. 3D).

\section{Effects of Muscle Attachments on Stress Response}

Functional integration strongly influenced the change in FA in response to stressful treatment (fig. 4; Levene's test: species: $F=9.51, P<.001$; integration category: $F=$ $6.04, P<.01)$. As a group, functionally integrated traits had a smaller increase in FA in male $S$. monticolus $(t=$ $-7.68, P=.001$; fig. $4 A), S$. hoyi $(t=-2.52, P=.014$; fig. $4 D)$, and female Sorex cinereus $(t=-2.92, P=.04$; fig. $4 C$ ). Change in trait sizes did not differ between functionally integrated and nonintegrated groups of traits and was not different from 0 in all species, except female $S$. monticolus (fig. 4).

\section{Changes in Functional Integration between Treatments}

Integration of trait sizes. In all species and under both treatments, the index of integration was greater among traits belonging to the same functional group than among nonintegrated traits (fig. 5; species: $F=3.79, P=.04$; integration category: $F=5.28, P<.001)$. Cohesiveness among traits tended to decrease in both integrated and nonintegrated traits in shrews raised under stressful conditions (fig. 5); the decrease in integration under stress reached statistical significance in $S$. cinereus (nonintegrated group only: $t=2.23, P=.03$; fig. $5 C$ ) and $S$. hoyi (both groups: $t>3.58, P<.01$; fig. $5 D)$.
Integration of fluctuating asymmetries. In all species and under both treatments, with the exception of $S$. cinereus (fig. $5 C$ ), the index of integration of FA of individual traits was greater for traits belonging to a functional group than for nonintegrated traits (species: $F=2.17, P=.05$; integration category: $F=3.24, P=.02$ ). Integration of $\mathrm{FA}$ of individual traits was significantly higher in shrews raised under control conditions than in shrews raised under stress $(t>2.7, P<.05$; fig. 5).

\section{Discussion}

Increase in developmental variation in extreme environments can be due to either novel directional selection on individual organismal components (Wagner and Altenberg 1996; Hadany and Beker 2003) or effects of a stressor on organism-wide homeostasis (Bradshaw and Hardwick 1989; Eshel and Matessi 1998; Schlichting and Pigliucci 1998; Gibson and Wagner 2000; Newman and Muller 2000; Nanjundiah 2003; Rutherford 2003; Gibson and Dworkin 2004). The former scenario might produce a more directional response to stress at the population level, because stress-induced variation is channeled and amplified by existing functional complexes, whereas the latter scenario might produce a greater opportunity for the evolution of novel morphological structures (Goldschmidt 1940; Schlichting and Pigliucci 1998; West-Eberhard 2003). Overall, the weakening of organismal integration, specifically of regulatory systems, may provide a mechanism behind the frequently documented association among morphological diversification, evolutionary change, and extreme environments.

We investigated changes in functional integration among the components of the foraging apparatus of shrews raised under control and stressful environments and found that traits differed in response to a stressor: functionally integrated traits accumulated fewer developmental errors than nonintegrated traits. Moreover, functionally integrated complexes of traits retained their high cohesiveness and, presumably, functionality, even when their individual components varied extensively under stressful treatment. In addition, we documented strong covariation of fluctuating asymmetries among components of functionally integrated groups of traits. These findings raise several questions. First, why did more functionally integrated traits express lower stress-induced developmental variation? Is resistance of functionally integrated complexes of traits to stress an outcome of their complexity, or is it a product of specialized stress-buffering systems? Second, what mechanisms maintain the cohesiveness of function- 
(A) Sorex monticolus
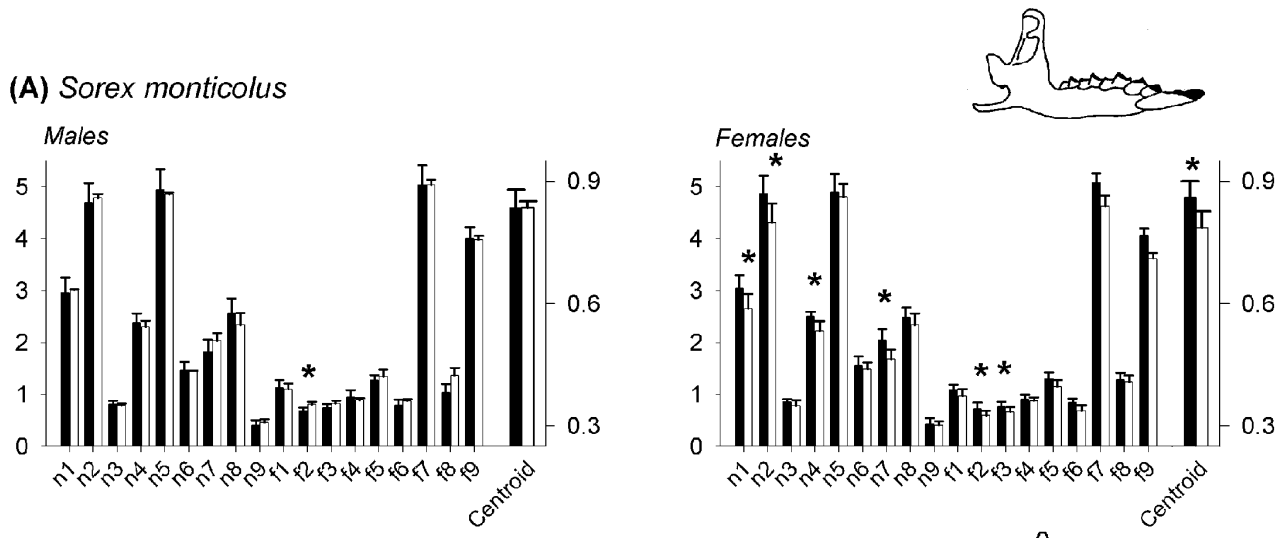

(B) Sorex vagrans

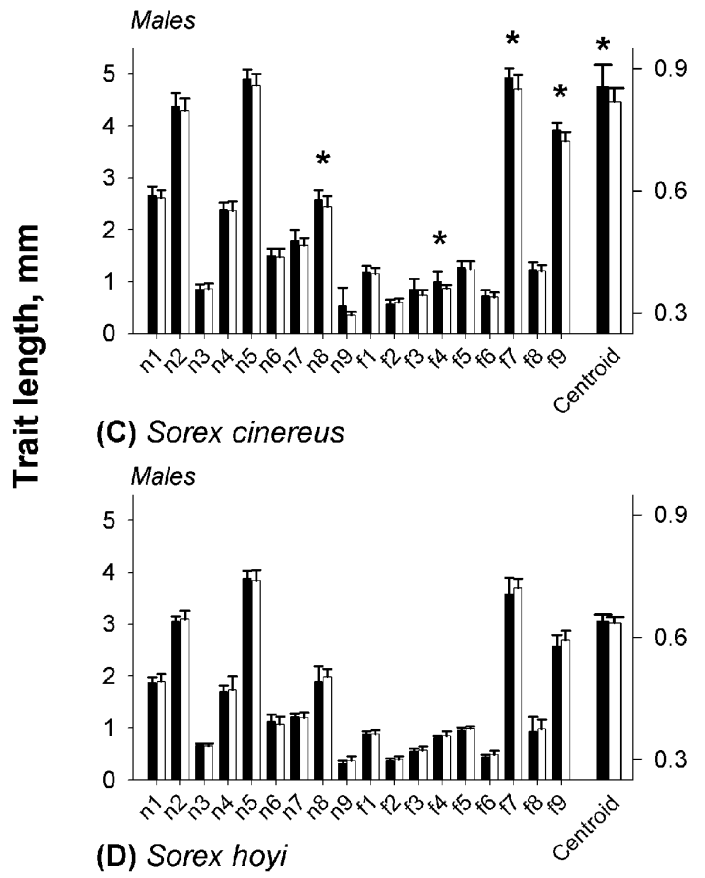

Females
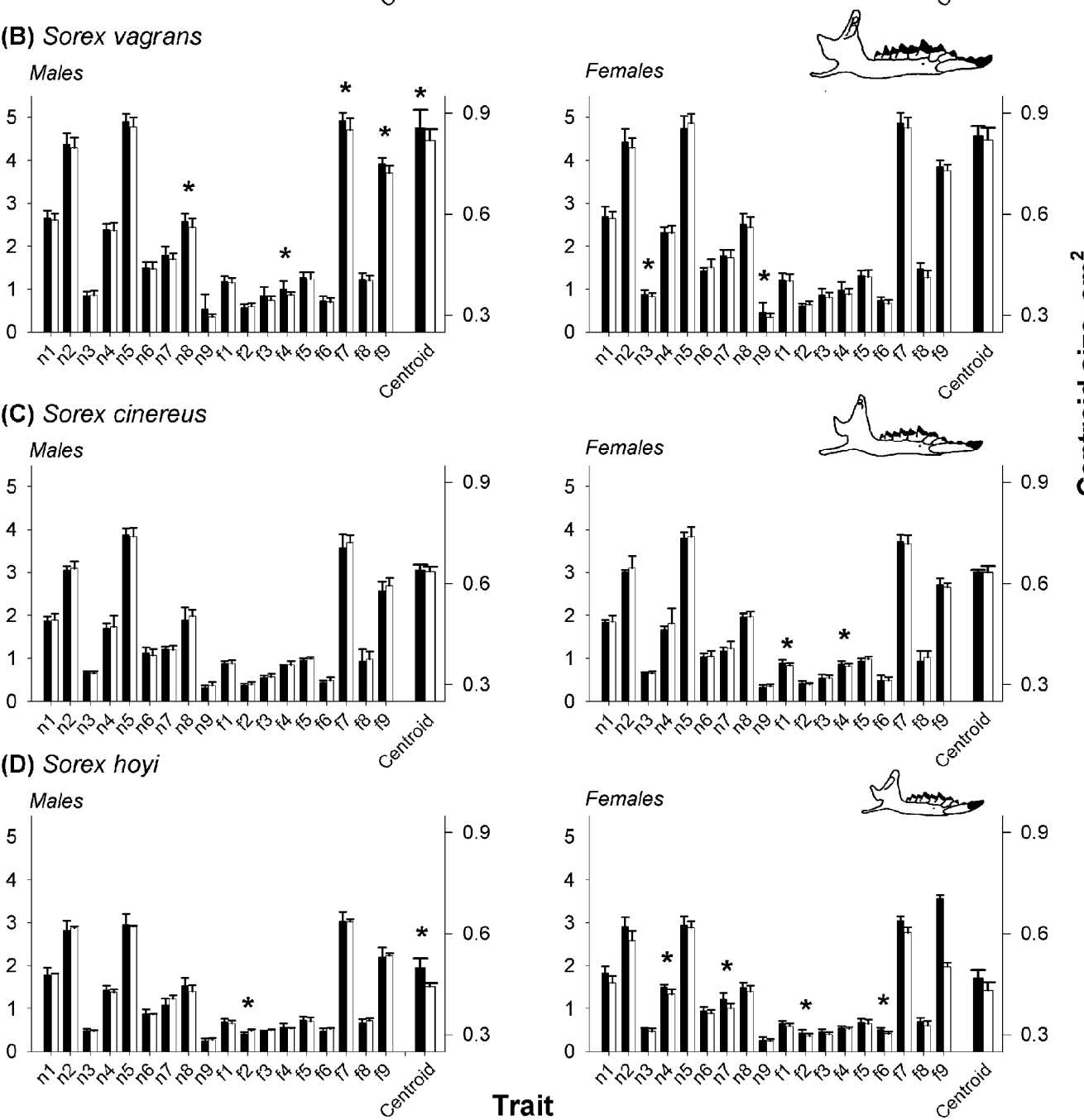

Figure 2: Means \pm SE of the two sides of 18 mandibular measurements and jaw size (centroid) under control (black bars) and vegetation removal (white bars) conditions in $(A)$ Sorex monticolus, $(B)$ Sorex vagrans, $(C)$ Sorex cinereus, and $(D)$ Sorex hoyi. Asterisk indicates significant difference between treatments after sequential within-species Bonferroni correction. Raw values are shown; ln-transformed data are used in analyses. 
(A) Sorex monticolus

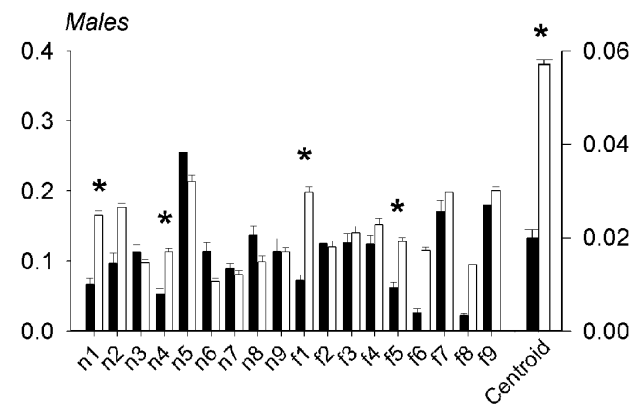

(B) Sorex vagrans

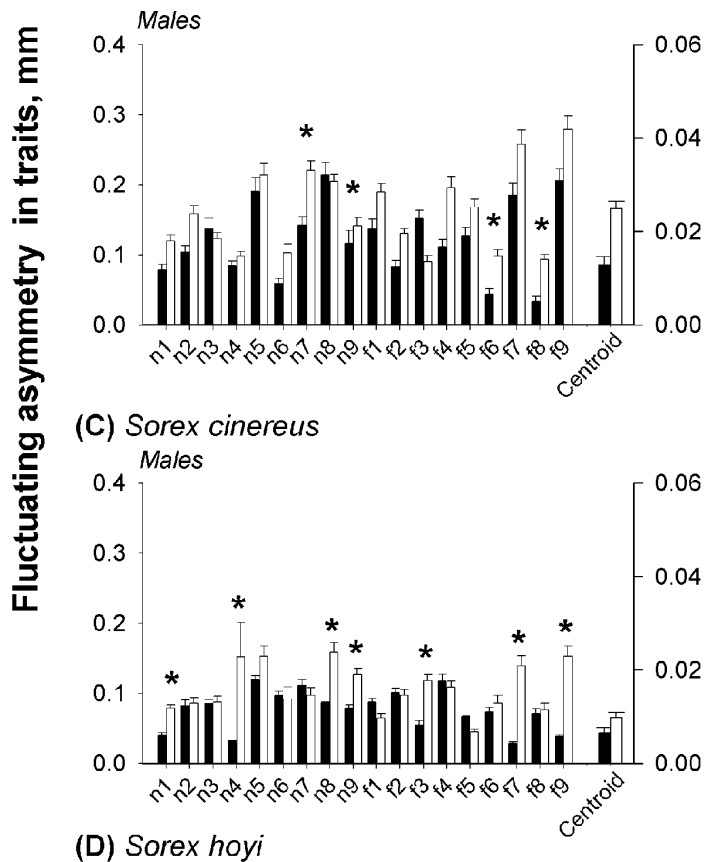

(D) Sorex hoyi



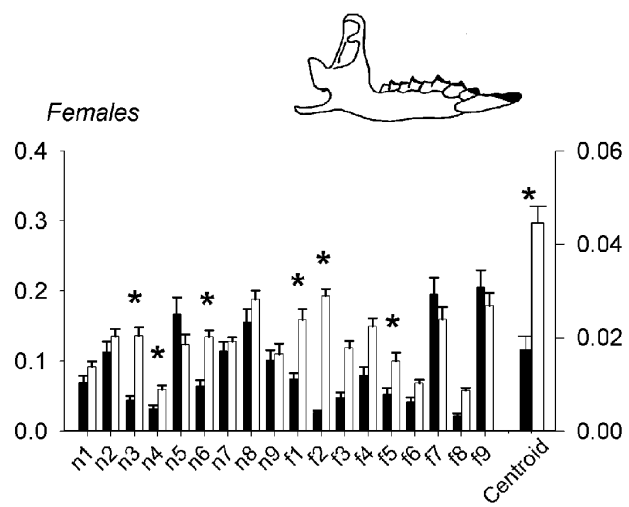
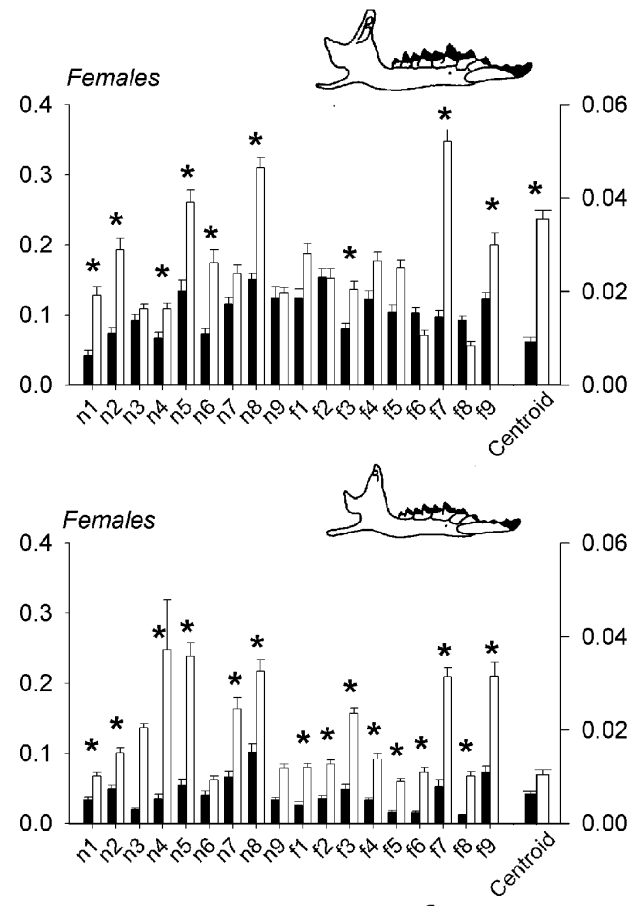

을

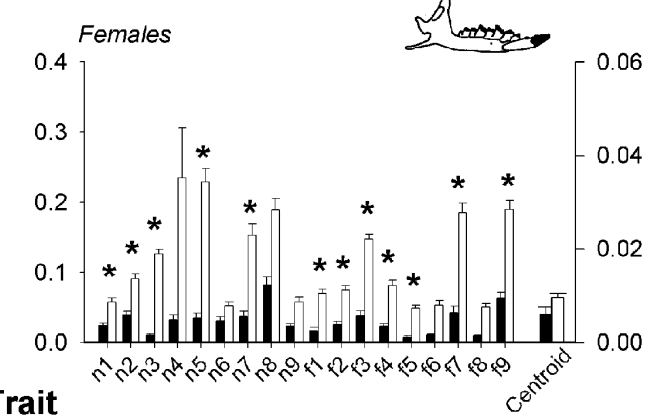

Figure 3: Fluctuating asymmetry (unsigned left- minus right-side values, mean $\pm \mathrm{SE}$ ) for 18 mandibular traits and jaw size (centroid) under control (black bars) and vegetation removal (white bars) conditions in (A) Sorex monticolus, (B) Sorex vagrans, $(C)$ Sorex cinereus, and $(D)$ Sorex hoyi. Asterisk indicates significant difference between habitat treatments in Levene's test of variance heterogeneity (treatment is entered as a fixed effect; mean squares due to individual are used in $F$ ratio denominator). The $P$ values are sequentially adjusted for multiple comparisons. Raw values are shown; ln-transformed data are used in analyses. 
(A) Sorex monticolus

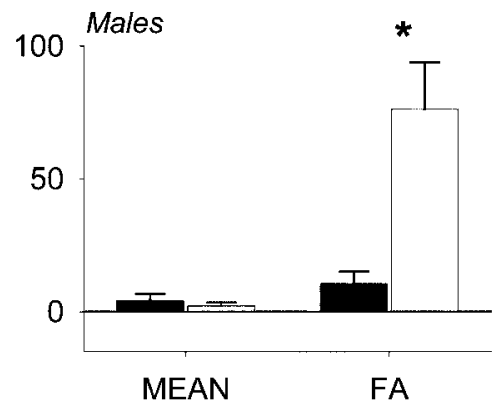

(B) Sorex vagrans

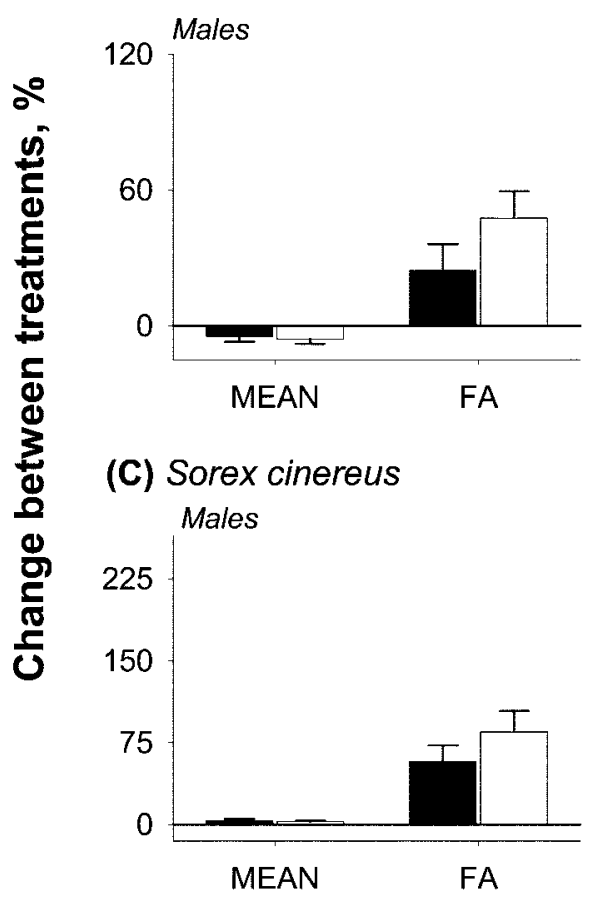

(D) Sorex hoyi

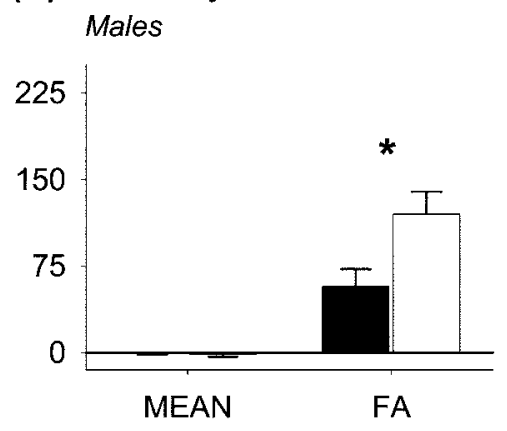

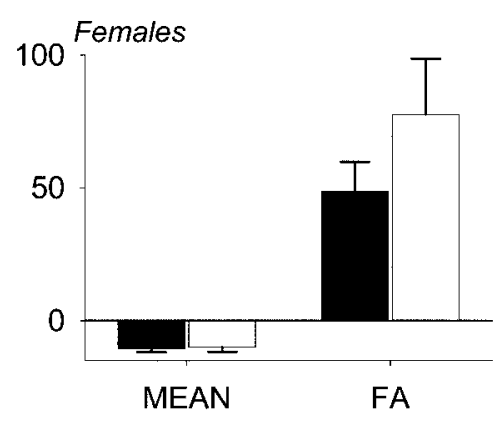
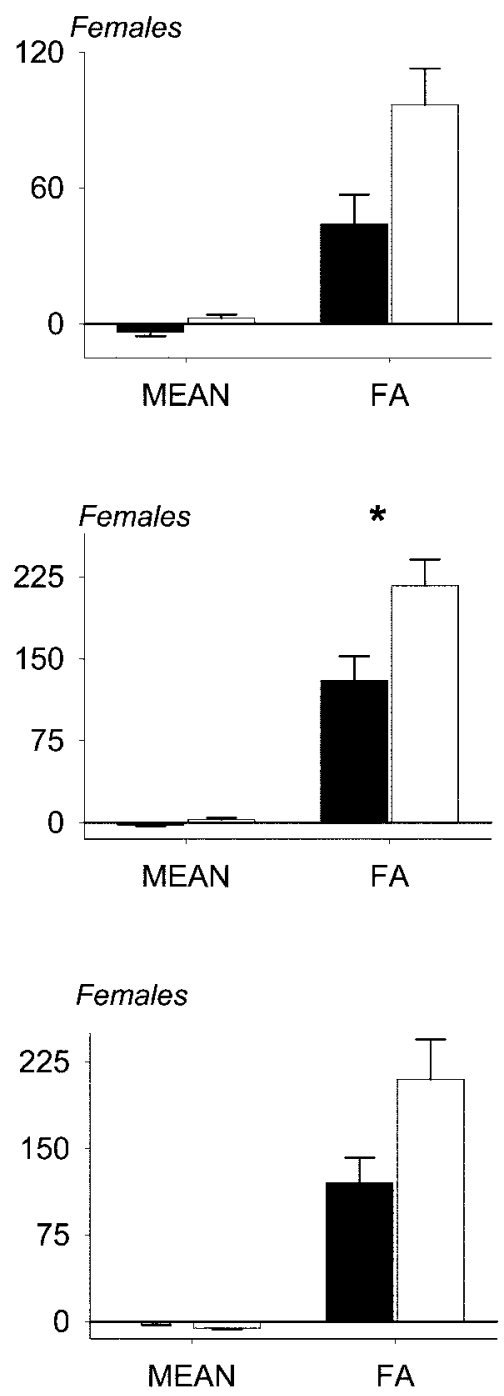

\section{Trait}

Figure 4: Percent change between control and vegetation removal treatments (VR minus control) in average size (MEAN) and average fluctuating asymmetry $(F A)$ for a group of functionally related (black bars) and nonintegrated (white bars) mandibular traits in $(A)$ Sorex monticolus, (B) Sorex vagrans, $(C)$ Sorex cinereus, and $(D)$ Sorex hoyi. Asterisk indicates significant difference between treatments. 
(A) Sorex monticolus

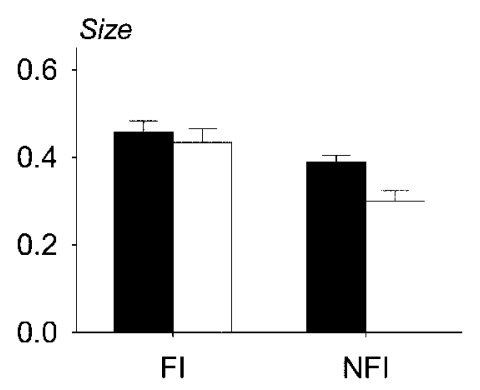

(B) Sorex vagrans

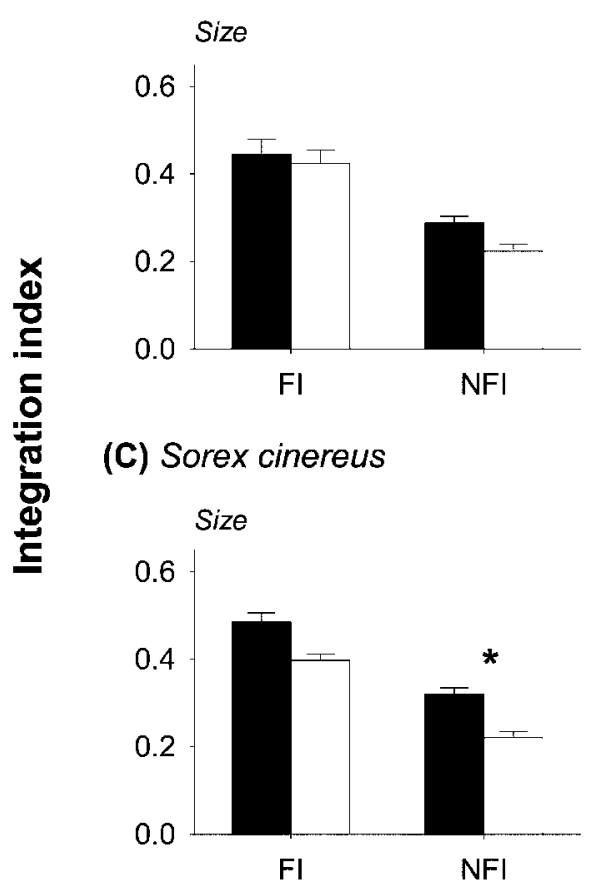

(D) Sorex hoyi

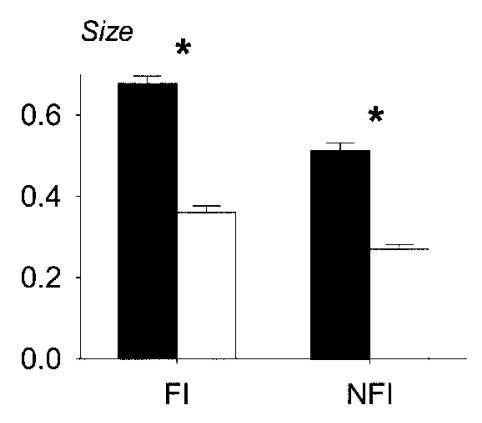

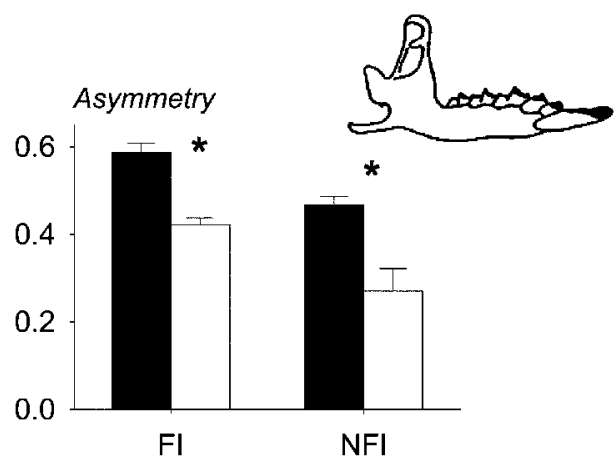
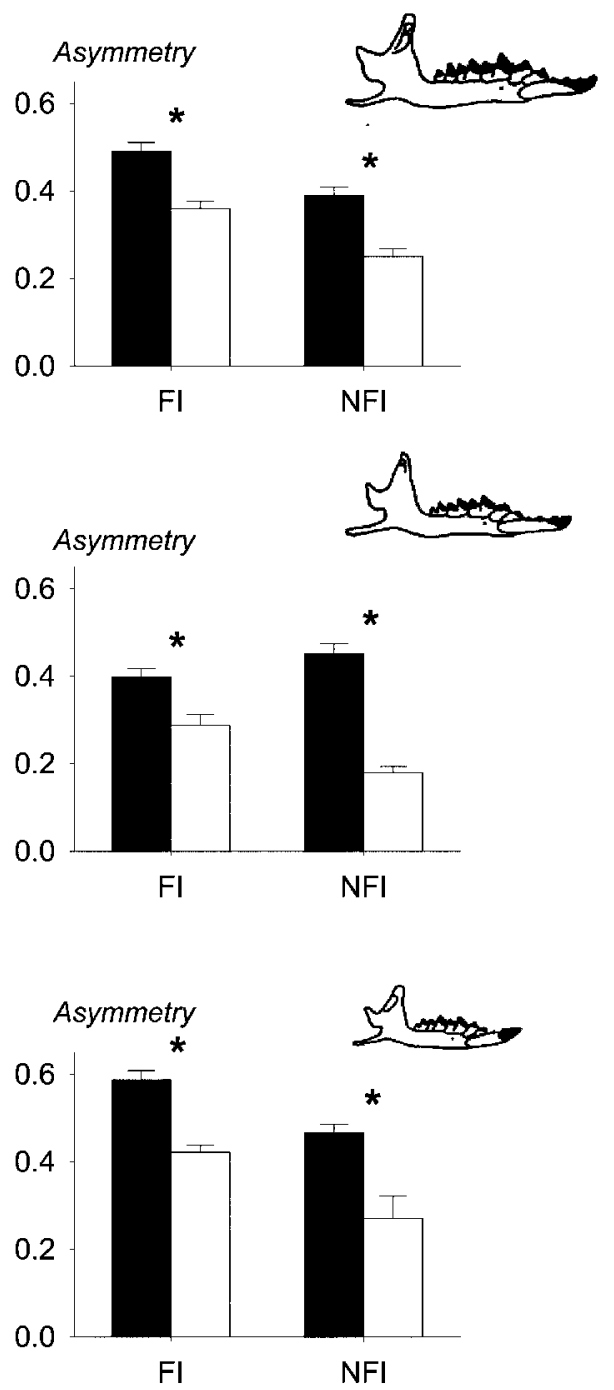

Functional integration, category

Figure 5: Index of integration among trait sizes (left) and traits' fluctuating asymmetries (right) in a group of functionally integrated (FI) and nonintegrated (NFI) mandibular traits under control (black bars) and vegetation removal (white bars) treatments in $(A)$ Sorex monticolus, (B) Sorex vagrans, $(C)$ Sorex cinereus, and $(D)$ Sorex hoyi. Asterisk indicates significant difference between treatments (size: $t>3.49, P<.03$; asymmetry: $t>$ $2.2, P<.05)$. 
ally integrated groups of traits under a stressful environment, and how do such mechanisms evolve?

Integration of fluctuating asymmetries among individual mandibular traits is expected when these traits share common developmental pathways, partition the same resource during growth, or have coordinated development maintained by organism-wide signaling (Riska 1986, 1989; Hall 2003; Hallgrímsson et al. 2003). In soricid shrews, development of integrated muscle attachment complexes and ossification of the lower jaw coincide with the onset of functional use (Foresman 1994; Foresman and Badyaev 2005), and thus integration of fluctuating asymmetries could be due to three main sources. First, integration of asymmetries can be due to shared early development (e.g., Wagner 1990; Polak et al. 2003). This mechanism would result in coordination of asymmetries among traits within functional complexes but would not produce a lower response to stress by these complexes (Hallgrímsson 1999; Hallgrímsson et al. 2004; Sun et al. 2004). Second, the integration of fluctuating asymmetries can be accomplished by compensatory functional interactions of the left and right sides of the homologous muscle attachment complexes (DuBrul and Laskin 1961; Hallgrímsson 1999; Legrell and Isberg 1999). Indeed, shrews have an unfused mandibular symphysis that enables coordination of left and right jaws during prey handling (Dötsch 1985). Thus, traits can grow and accumulate developmental errors separately, and close coordination between left and right jaws during use can provide a source of integration of fluctuating asymmetries between the sides. This mechanism would also result in coordination of asymmetries within functional units but would not predict lower expression of stress-induced variance by functionally integrated traits in the absence of changes in patterns of integration or in trait sizes (Huang et al. 1994; Herring et al. 2001). Finally, the integration of fluctuating asymmetries can be accomplished by channeling of stress-induced variation by functional systems during development (e.g., Moss and Salentijn 1969; Roth and Wake 1985; Hallgrímsson et al. 2004). As a functional group of traits develops, its integration of developmental noise will increase because of the compensatory and constraining interactions among a greater number of linked components (Swaddle and Witter 1997; Badyaev 1998; Hallgrímsson 1999; Aparicio and Bonal 2002; Foresman and Badyaev 2005; Hallgrímsson et al. 2004), which then can accommodate the effects of stressful perturbations without the loss of function. For functionally linked groups of traits, this mechanism would predict both coordinated expression of fluctuating asymmetries within groups of traits and lower accumulation of developmental errors (Baatz and Wagner 1997; Rice 1998; Waxman and Peck 1998; Meiklejohn and Hartl 2002; Siegal and Bergman 2002), as indeed found in this study (fig.
5). Alternatively, greater survival of individuals with greater integration among components of their functional units can result in their overrepresentation in the poststress sample. Below we review these explanations.

The effect of stress depends closely on its timing in the organism's ontogeny (Bradshaw and Hardwick 1989; Huether 1996; Badyaev 2005). Stress exposure during late growth typically affects only a small group of weakly integrated and late-maturing traits (Hallgrímsson 1998; Reichling and German 2000). In contrast, early exposure to stress not only makes the ontogeny of morphological structures more amenable to subsequent modification (Wimberger 1991; Neyfakh and Hartl 1993; Hanken et al. 1997) but also can direct morphological variation. For example, if morphological traits differ in sequence of ossification, then morphological variation in later-ossified components can be directed by stress-induced modifications of earlier-ossified components (Helm and German 1996; Mabee et al. 2000; Reichling and German 2000; Badyaev and Foresman 2004). Moreover, when individuals in a population are synchronous in their development, accommodation and channeling of stress-induced variation during ontogeny by existing morphological structures lead to similar and simultaneous reorganization in many individuals (Chapin et al. 1993; Jablonka and Lamb 1995), thereby creating a cohort of individuals with similar phenotypic patterns (Goldschmidt 1940; Oyama 2000; WestEberhard 2003; Badyaev 2005). Shrew species in this study have a relatively short life span (10-12 months) and highly synchronized breeding cycles-in the study populations, most individuals were born within a month of each other (Foresman and Long 1998; Gillihan and Foresman 2004). Thus, a large cohort of individuals develops under similar environmental conditions. Similarity among individuals in the patterns of response to stress documented in this and other studies of shrews (Badyaev and Foresman 2000, 2004; Badyaev et al. 2000; Foresman and Badyaev 2005; R. L. Young and A. V. Badyaev, unpublished manuscript), as well as other animals (Leamy 1993; Sowry and Badyaev 1999; Juste et al. 2001; Klingenberg et al. 2001), could be due to the similar effects of temporal changes in developmental integration on expression of stress-induced developmental variation (Cheverud 1982; Debat and David 2001; Meiklejohn and Hartl 2002; Hallgrímsson et al. 2004).

What is the ecological and evolutionary importance of accommodation of stress-induced variation during development in shrews? Short generation time and limited dispersal of shrews might favor the evolution of mechanisms that enable the environment during growth to guide development of the adult form (Badyaev and Foresman 2004; Badyaev 2005; R. L. Young and A. V. Badyaev, unpublished manuscript). Indeed, the overlap between the ossification 
sequence and functional use should facilitate production of locally favored mandibular structures (Herring 1993). Morphological structures and integration patterns in shrew mandibles vary with environmental conditions (Pankakoski et al. 1992; Badyaev et al. 2000), population density (Zakharov et al. 1991), and coexistence with similarly sized species (Foresman and Badyaev 2005). Remarkably, however, such environmentally induced structures have similar patterns of functional integration not only among individuals within the same population (fig. 5) but also across shrew species (Badyaev and Foresman 2000, 2004; R. L. Young and A. V. Badyaev, unpublished manuscript). Species were most distinct in variation in traits that were not integrated functionally within each species. This suggests that the retention of integration among functionally related traits under stress has a heritable basis. Interestingly, several traits in this study showed an increase in directional asymmetry under stress (table 1 ), suggesting that growth-related variation and developmental noise can be expressed by the same developmental mechanisms and that response to stress can involve directional change in developmental mechanisms (e.g., Lens and Van Dongen 2000). Alternatively, similarity in integration patterns among species can reflect recurrence of similar selection pressures among species and environments. Indeed, populations of Sorex cinereus and Sorex vagrans, which compete for prey of similar size, showed concordant and reversible displacement of integration patterns when they co-occurred in the same area (Foresman and Badyaev 2005).

Retention and inheritance of stress-induced variation by an organism can be facilitated either by recurrent and similar developmental stressors or by the complexity of developmental systems. Here we showed that whereas shrews growing in extreme environments had reduced integration among mandibular traits, groups of functionally related traits remained highly integrated under stress primarily because of the compensatory and accommodating effects of their developmental interactions. Alternatively, this pattern can be produced by differential mortality of individuals with varying degree of integration. To address this explanation, we will examine the ontogeny of integration under two selective regimes, specifically addressing the effects of the ossification sequence on the channeling of stress-induced phenotypic variation. In general, accommodation and channeling of stress-induced variation during development might facilitate phenotypic and genetic assimilation of response to a stressor (Schmalhausen 1949; Waddington 1952; West-Eberhard 2003; Palmer 2004). Together with stress-induced changes in population dynamics, such as fluctuations in developmental synchrony and population sizes, such accommodation, if induced in a large cohort of individuals simultaneously, can significantly facilitate the rate of adaptive evolution.

\section{Acknowledgments}

We thank C. Fiumara and M. Fernandes for digitizing shrew mandibles; R. McGraw and G. Parkhurst for help with collection of shrews; R. Duckworth, E. Lindstedt, K. Oh, and D. Seaman for discussion; and two anonymous reviewers for exceptionally helpful comments and suggestions incorporated in the manuscript's revisions. This study was partially funded by the National Science Foundation (grants DEB-0075388, DEB-0077804, and IBN0218313) and the University of Arizona.

\section{Literature Cited}

Alberch, P. 1980. Ontogenesis and morphological diversification. American Zoologist 20:653-667.

Ancel, L. W. 1999. A quantitative model of the Simpson-Baldwin effect. Journal of Theoretical Biology 196:197-209.

Aparicio, J. M., and R. Bonal. 2002. Why do some traits show higher fluctuating asymmetry than others? a test of hypotheses with tail feathers of birds. Heredity 89:139-144.

Ärnbäck-Christie-Linde, A. 1907. Der Bau der Soriciden und ihre Beziehungen zu andern Säugetieren. Gegenbaurs Morphologisches Jahrbuch 36:463-514.

Baatz, M., and G. P. Wagner. 1997. Adaptive inertia caused by hidden pleiotropic effects. Theoretical Population Biology 51:49-66.

Badyaev, A. V. 1998. Environmental stress and developmental stability in dentition of the Yellowstone grizzly bears. Behavioral Ecology 9:339-344.

- 2005. Stress-induced variation in evolution: from behavioral plasticity to genetic assimilation. Proceedings of the Royal Society of London B 272:877-886.

Badyaev, A. V., and K. R. Foresman. 2000. Extreme environmental change and evolution: stress-induced morphological variation is strongly concordant with patterns of evolutionary divergence in shrew mandibles. Proceedings of the Royal Society of London B 267:371-377.

- 2004. Evolution of morphological integration. I. Functional units channel stress-induced variation. American Naturalist 163: 868-879.

Badyaev, A. V., K. R. Foresman, and M. V. Fernandes. 2000. Stress and developmental stability: vegetation removal causes increased fluctuating asymmetry in shrews. Ecology 81:336-345.

Bijlsma, R., and V. Loeschcke. 1997. Environmental stress, adaptation and evolution. Birkhauser, Basel.

Bradshaw, A. D., and K. Hardwick. 1989. Evolution and stress: genotypic and phenotypic components. Biological Journal of the Linnean Society 37:137-155.

Caropale, L. H. 1999. Chance favors the prepared genome. Annals of the New York Academy of Sciences 870:1-21.

Chapin, F. S., III, K. Autumn, and F. Pugnaire. 1993. Evolution of suites of traits in response to environmental stress. American Naturalist 142(suppl.):S78-S92.

Cheverud, J. M. 1982. Phenotypic, genetic, and environmental morphological integration in the cranium. Evolution 36:499-516.

Cheverud, J. M., J. J. Rutledge, and W. R. Atchley. 1983. Quantitative 
genetics of development: genetic correlations among age-specific trait values and the evolution of ontogeny. Evolution 37:895-905.

Dannelid, E. 1994. Comparison of pigment and other dental characters of eastern Palearctic Sorex (Mammalia: Soricidae). Pages 217-231 in J. F. Merritt, G. L. J. Kirkland, and R. K. Rose, eds. Advances in the biology of shrews. Carnegie Museum of Natural History, Pittsburgh.

Debat, V., and P. David. 2001. Mapping phenotypes: canalization, plasticity and developmental stability. Trends in Ecology \& Evolution 16:555-561.

Dötsch, C. 1985. Masticatory function in shrews (Soricidae). Acta Zoologica Fennica 173:231-235.

- 1986. Mastication in the musk shrew, Suncus murinus (Mammalia, Soricidae). Journal of Morphology 189:25-43.

DuBrul, E. L., and D. M. Laskin. 1961. Preadaptive potentialities of the mammalian skull: an experiment in growth and form. American Journal of Anatomy 109:117-132.

Eshel, I., and C. Matessi. 1998. Canalization, genetic assimilation and preadaptation: a quantitative genetic model. Genetics 149:21192133.

Fearnhead, R. W., C. C. D. Shute, and A. D. A. Bellairs. 1955. The temporo-mandibular joint of shrews. Proceedings of the Zoological Society of London 125:795-806.

Foresman, K. R. 1994. Comparative embryonic development of the Soricidae. Pages 241-258 in J. F. Merritt, G. L. J. Kirkland, and R. K. Rose, eds. Advances in the biology of shrews. Carnegie Museum of National History, Pittsburgh.

Foresman, K. R., and A. V. Badyaev. 2005. Developmental instability and the environment: why are some species better indicators of stress than others? Pages 1-17 in J. F. Merritt, S. Churchfield, R. Hutterer, and B. A. Sheftel, eds. Advances in the biology of shrews. Carnegie Museum of Natural History, Pittsburgh.

Foresman, K. R., and R. D. Long. 1998. The reproductive cycle of the vagrant shrew (Sorex vagrans) and the common shrew (Sorex cinereus) in Montana. American Midland Naturalist 139:108-113.

Gaughran, G. R. L. 1954. A comparative study of the osteobiology and myology of the cranial and cervical regions of the shrew, Blarina brevicauda, and the mole, Scalopus aquaticus. Miscellaneous Publications Museum of Zoology University of Michigan 80:1-82.

Gibson, G., and I. Dworkin. 2004. Uncovering cryptic genetic variation. Nature Reviews 5:681-690.

Gibson, G., and G. P. Wagner. 2000. Canalization in evolutionary genetics: a stabilizing theory? BioEssays 22:372-380.

Gillihan, S. W., and K. R. Foresman. 2004. Sorex vagrans. Mammalian Species 744:1-5.

Goldschmidt, R. B. 1940. The material basis of evolution. Yale University Press, New Haven, CT.

Hadany, L., and T. Beker. 2003. On the evolutionary advantage of fitness-associated recombination. Genetics 165:2167-2179.

Hall, B. K. 2003. Unlocking the black box between genotype and phenotype: cell condensations as morphogenetic (modular) units. Biology and Philosophy 18:219-247.

Hallgrímsson, B. 1998. Fluctuating asymmetry in the mammalian skeleton: evolutionary and developmental implications. Evolutionary Biology 30:187-251.

1999. Ontogenetic patterning of skeletal fluctuating asymmetry of rhesus macaques and human: evolutionary and developmental implications. International Journal of Primatology 20: $121-151$.
Hallgrímsson, B., T. Miyake, K. Wilmore, and B. K. Hall. 2003. The embryological origins of developmental stability: size, shape and fluctuating asymmetry in prenatal random bred mice. Journal of Experimental Zoology B 296:40-57.

Hallgrímsson, B., K. Willmore, C. Dorval, and D. M. L. Cooper. 2004. Craniofacial variability and modularity in macaques and mice. Journal of Experimental Zoology B 302:207-225.

Hanken, J., M. W. Klymkowsky, K. E. Alley, and D. H. Jennings. 1997. Jaw muscle development as evidence for embryonic repatterning in direct-development frogs. Proceedings of the Royal Society of London B 264:1349-1354.

Helm, J. W., and R. Z. German. 1996. The epigenetic impact of weaning on craniofacial morphology during growth. Journal of Experimental Zoology 276:243-253.

Herring, S. W. 1993. Epigenetic and functional influences on skull growth. Pages 153-206 in J. Hanken and B. K. Hall, eds. The skull. University of Chicago Press, Chicago.

Herring, S. W., K. L. Rafferty, Z. J. Liu, and C. D. Marshall. 2001. Jaw muscles and the skull in mammals: the biomechanics of mastication. Comparative Biochemistry and Physiology A 131:207219.

Hoffmann, A. A., and M. J. Hercus. 2000. Environmental stress as an evolutionary force. BioScience 50:217-226.

Hoffmann, A. A., and P. A. Parsons. 1997. Extreme environmental change and evolution. Cambridge University Press, Cambridge.

Huang, X., G. Zhang, and S. W. Herring. 1994. Age changes in the mastication in the pig. Comparative Biochemistry and Physiology A 107:647-654.

Huether, G. 1996. The central adaptation syndrome: psychosocial stress as a trigger for adaptive modifications of brain structure and brain function. Progress in Neurobiology 48:569-612.

Imasheva, A. G. 1999. Environmental stress and genetic variation in animal populations. Russian Journal of Genetics 35:343-351.

Jablonka, E., and M. J. Lamb. 1995. Epigenetic inheritance and evolution: the Lamarckian dimension. Oxford University Press, Oxford.

Juste, J., C. Lopez-Gonzalez, and R. E. Strauss. 2001. Analysis of asymmetries in the African fruit bats Eidolon helvum and Rousettus egyptiacus (Mammalis: Magachiroptera) from the islands of the Gulf of Guinea. II. Integration and levels of multivariate fluctuating asymmetry across a geographical range. Journal of Evolutionary Biology 14:672-680.

Klingenberg, C. P., and G. S. McIntyre. 1998. Geometric morphometrics of developmental instability: analyzing patterns of fluctuating asymmetry with Procrustes methods. Evolution 53:13631375.

Klingenberg, C. P., A. V. Badyaev, S. M. Sowry, and N. J. Beckwith. 2001. Inferring developmental modularity from morphological integration: analysis of individual variation and asymmetry in bumblebee wings. American Naturalist 157:11-23.

Lauder, G. V. 1981. Form and function: structural analysis in evolutionary morphology. Paleobiology 7:430-442.

Leamy, L. J. 1993. Morphological integration of fluctuating asymmetry in the mouse mandible. Genetica 89:139-153.

Legrell, P. E., and A. Isberg. 1999. Mandibular length and midline asymmetry after experimentally induced temporomandibular joint disk displacement in rabbits. American Journal of Orthodontics and Dentofacial Orthopedics 115:247-253.

Lens, L., and S. Van Dongen. 2000. Fluctuating and directional asymmetry in natural bird populations exposed to different levels of 
habitat disturbance, as revealed by mixture analysis. Ecology Letters 3:516-522.

Lipson, H., J. B. Pollack, and N. P. Suh. 2002. On the origin of modular variation. Evolution 56:1549-1556.

Mabee, P. M., K. L. Olmstead, and C. C. Cubbage. 2000. An experimental study of intraspecific variation, developmental timing, and heterochrony in fishes. Evolution 54:2091-2106.

Meiklejohn, C. D., and D. L. Hartl. 2002. A single mode of canalization. Trends in Ecology \& Evolution 17:468-473.

Meyer, A. 1990. Morphometrics and allometry in the trophically polyphenic cichlid fish, Cichlasoma citrinellum: alternative adaptations and ontogenetic changes in shape. Journal of Zoology (London) 221:237-260.

Moss, M. L., and L. Salentijn. 1969. The primary role of functional matrices in facial growth. American Journal of Orthodontics 55: 566-577.

Nanjundiah, V. 2003. Phenotypic plasticity and evolution by genetic assimilation. Pages 245-263 in G. B. Muller and S. Newman, eds. Origination of organismal form: beyond the gene in developmental and evolutionary biology. MIT Press, Cambridge, MA.

Newman, S. A., and G. B. Muller. 2000. Epigenetic mechanisms of character origination. Journal of Experimental Zoology 288:304314.

Neyfakh, A. A., and D. L. Hartl. 1993. Genetic control of the rate of embryonic development: selection for faster development at elevated temperatures. Evolution 47:1625-1631.

Nijhout, H. F. 2002. The nature of robustness in development. BioEssays 24:553-563.

Oyama, S. 2000. The ontogeny of information: developmental systems and evolution. Duke University Press, Durham, NC.

Palmer, A. R. 2004. Symmetry breaking and the evolution of development. Science 306:828-833.

Palmer, A. R., and C. Strobeck. 2003. Fluctuating asymmetry analyses revisited. Pages 279-319 in M. Polak, ed. Developmental instability: causes and consequences. Oxford University Press, Oxford.

Pankakoski, E., I. Koivisto, and H. Hyvärinen. 1992. Reduced developmental stability as an indicator of heavy metal pollution in the common shrew Sorex araneus. Acta Zoologica Fennica 191: 137-144.

Polak, M., A. P. Moller, S. W. Gangestad, D. E. Kroeger, J. T. Manning, and R. Thornhill. 2003. Does an individual asymmetry parameter exist? a meta-analysis. Pages 81-98 in M. Polak, ed. Developmental instability: causes and consequences. Oxford University Press, Oxford.

Price, T. D., A. Qvarnstrom, and D. E. Irwin. 2003. The role of phenotypic plasticity in driving genetic evolution. Proceedings of the Royal Society of London B 270:1433-1440.

Reichling, T. D., and R. Z. German. 2000. Bones, muscles and visceral organs of protein-malnourished rats (Rattus norvegicus) grow more slowly but for longer durations to reach normal final size. Journal of Nutrition 130:2326-2332.

Rice, S. H. 1998. Evolution of canalization and the breaking of von Baer's laws: modeling the evolution of development with epistasis. Evolution 52:647-656.

Riska, B. 1986. Some models for development, growth, and morphometric correlation. Evolution 40:1303-1311.

. 1989. Composite traits, selection response, and evolution. Evolution 43:1172-1191.

Rohlf, F. J., and D. Slice. 1990. Extensions of the Procrustes method for the optimal superimposition of landmarks. Systematic Zoology 39:40-59.

Roth, G., and D. B. Wake. 1985. Trends in the functional morphology and sensorimotor control of feeding behavior in salamanders: an example of the role of internal dynamics in evolution. Acta Biotheoretica 34:175-192.

Rutherford, S. L. 2003. Between genotype and phenotype: protein chaperones and evolvability. Nature Reviews 4:263-274.

SAS Institute. 1989. SAS/STAT user's guide. SAS Institute, Cary, NC. Schlichting, C. D., and M. Pigliucci. 1998. Phenotypic evolution: a reaction norm perspective. Sinauer, Sunderland, MA.

Schlichting, C. D., and H. Smith. 2002. Phenotypic plasticity: linking mechanisms with evolutionary outcomes. Evolutionary Ecology 16:189-211.

Schmalhausen, I. I. 1949. Factors of evolution. Blakiston, Philadelphia.

Sharma, D. R. 1958. Studies on the anatomy of the Indian insectivore, Suncus murinus. Journal of Morphology 102:427-553.

Siegal, M. L., and A. Bergman. 2002. Waddington's canalization revisited: developmental stability and evolution. Proceedings of the National Academy of Sciences of the USA 99:10528-10532.

Smits, J. D., F. Witte, and G. D. E. Povel. 1996a. Differences between inter- and intraspecific architectonic adaptations to pharyngeal mollusc crushing in cichlid fishes. Biological Journal of the Linnean Society 59:367-387.

Smits, J. D., F. Witte, and F. G. Van Veen. 1996b. Functional changes in the anatomy of the pharyngeal jaw apparatus of Astatoreochromis alluaudi (Pisces, Cichlidae), and their effects on adjacent structures. Biological Journal of the Linnean Society 59:389-409.

Sowry, S. M., and A. V. Badyaev. 1999. Does developmental integration mediate trait response to environmental stress? experiment with bumblebee (Bombus impatiens) wing venation pattern and $\mathrm{CO}_{2}$ exposure. Honors thesis. University of Montana, Missoula.

Sun, Z., E. Lee, and S. W. Herring. 2004. Cranial sutures and bones: growth and fusion in relation to masticatory strain. Anatomical Record A 276:150-161.

Swaddle, J. P., and M. S. Witter. 1997. On the ontogeny of developmental stability in a stabilized trait. Proceedings of the Royal Society of London B 264:329-334.

Thompson, E. N., A. R. Biknevicius, and R. Z. German. 2003. Ontogeny of feeding function in the gray short-tailed opossum Monodelphis domestica: empirical support for the constrained model of jaw biomechanics. Journal of Experimental Biology 206:923-932.

Waddington, C. H. 1941. Evolution of developmental systems. Nature 147:108-110.

. 1952. Genetic assimilation of an acquired character. Evolution 7:118-126.

Wagner, G. P. 1990. A comparative study of morphological integration in Apis mellifera (Insecta, Hymenoptera). Zeitschrift für Zoologische Systematik und Evolutionsforschung 28:48-61.

Wagner, G. P., and L. Altenberg. 1996. Complex adaptation and the evolution of evolvability. Evolution 50:967-976.

Wagner, G. P., G. Booth, and H. Bagheri-Chaichian. 1997. A population genetic theory of canalization. Evolution 51:329-347.

Waxman, D., and J. R. Peck. 1998. Pleiotropy and the preservation of perfection. Science 279:1210-1213.

West-Eberhard, M. J. 1989. Phenotypic plasticity and the origins of diversity. Annual Review of Ecology and Systematics 20:249-278. - 2003. Developmental plasticity and evolution. Oxford University Press, Oxford. 
Wills, C. 1983. The possibility of stress-triggered evolution. Lecture Notes in Biomathematics 53:299-312.

Wimberger, P. H. 1991. Plasticity of jaw and skull morphology in the neotropical cichlids Geophagus brasiliensis and G. steindachneri. Evolution 45:1545-1563.

Zakharov, V. M., E. Pankakoski, B. I. Sheftel, A. Peltonen, and I.
Hanski. 1991. Developmental stability and population dynamics in the common shrew, Sorex araneus. American Naturalist 138: 797-810.

Associate Editor: Günter P. Wagner Editor: Jonathan B. Losos 